\title{
DISCURSOS SOBRE NACIÓN Y PATRIA EN EL ANARQUISMO ESPAÑOL DE ENTRE SIGLOS
}

\author{
DISCOURSES ON NATION AND HOMELAND IN SPANISH \\ ANARCHISM IN THE TURN OF THE 19TH TO 2OTH CENTURIES
}

\author{
Ángeles Barrio Alonso* \\ Universidad de Cantabria, Santander, España
}

\begin{abstract}
RESUMEN: La doble identidad clase/nación no ha sido un objeto de conocimiento privilegiado de la historiografía social, aunque haya constancia de que, como procesos de construcción identitaria, operen habitualmente en paralelo. La idea de clase no era una cuestión central en el pensamiento anarquista cuyo discurso emancipador, universalista y cosmopolita, se dirigía a la humanidad en su conjunto y no sólo a los trabajadores. Sin embargo, la idea de nación, como la de patria, y sus expresiones derivadas, nacionalismo y patriotismo, formaban parte del discurso anarquista de impugnación del Estado y sus instituciones. Pero en ambos casos, la cuestión de las identidades adquiría formulaciones muy diversas e, incluso, aparentemente contradictorias.
\end{abstract}

PALABRAS CLAVE: anarquismo, clase, nación, nacionalismo, patria, patriotismo.

ABSTRACT: The Spanish social historiography did not show much interest on the question of dual identity class/nation. The idea of class was not a central issue in anarchist thought whose emancipatory, universalist and cosmopolitan discourse was addressed to humanity as a whole, and not only to working class. However, the idea of nation, like that of homeland, and its expressions -nationalism and patriotism - were an essential part of the anarchist discourse of challenge of the State and its institutions. But in both cases, the question of identities acquired in the not univocal anarchist discourse, a very diverse and, even apparently, contradictory formulations.

KEYWORDS: anarchism, class, nation, nationalism, homeland, patriotism.

* Correspondencia a: Ángeles Barrio Alonso. Departamento de Historia Moderna y Contemporánea. Facultad de Filosofía y Letras. Universidad de Cantabria. Avda. Los Castros s.n. 39005 Santander - barrioa@unican.es; maria.barrio@unican.es https://orcid.org/0000-0002-8998-9438

Cómo citar: Barrio Alonso, Ángeles (2021). «Discursos sobre nación y patria en el anarquismo español de entre siglos»; Historia Contemporánea, 66, 403-432. (https://doi.org/10.1387/hc.21236).

Recibido: 12 noviembre, 2019; aceptado: 2 junio, 2020.

ISSN 1130-2402 - elSSN 2340-0277 / ㄷ 2020 UPV/EHU 
Ángeles Barrio Alonso

\section{La cuestión de la doble identidad clase/nación en el anarquismo}

Las categorías de clase y nación no fueron nunca centrales en el discurso de condena radical del capitalismo y el Estado en el anarquismo ${ }^{1}$. La nación para los anarquistas es una consecuencia del Estado y la patria un invento de la burguesía, cuya impugnación va implícita a la de su causa. La clase, en el horizonte emancipador de su filosofía, es una abstracción inútil ya que la regeneración del individuo a la que aspira, la trasciende al dirigirse, a través de la imagen irénica e igualitaria de la futura sociedad libertaria, a la humanidad en su conjunto y no solo a los trabajadores. Un reduccionismo conceptual - no de ideas - aparentemente contradictorio con las formulaciones hiperbólicas del anarquismo contra el poder y la dominación de unos hombres por otros.

La cuestión de la identidad nacional en el obrerismo no ha sido objeto de especial interés para la historiografía social española, probablemente porque durante años la consideró «irrelevante» frente a la identidad de clase $^{2}$. La historiografía internacional de los movimientos romántico-nacionalistas, independentistas y anticolonialistas, sin embargo, sí que mostró interés por ella y, en el caso del anarquismo, no pasó por alto su defensa ocasional de la causa de los «nacionalismos débiles» frente a los «fuertes» - la de Kropotkin a favor del nacionalismo serbio no fue la única, aunque quizá sea la más conocida-, una postura contradictoria con el característico internacionalismo y cosmopolitismo gestado en las migraciones y exilios de los anarquistas por todo el mundo, y que tanto les diferenciaba de los socialistas. La obra de Benedict Anderson Bajo tres banderas, definida por su autor como un intento de representar «la fuerza gravitatoria del anarquismo entre nacionalismos militantes de lados opuestos del planeta ${ }^{3}$, confirma la experiencia cosmopolita que marcaba esa distancia entre marxistas y anarquistas ante la cuestión del colonialismo en el fin de siglo, y es, asimismo, un ejemplo de cómo, a través de la vida y la obra de algunas figuras destacadas, como Isabelo de los Reyes, José Rizal o José Martí, se desvelan facies inéditas del anarquismo español en los procesos insurreccionales independentistas de Cuba y Filipinas.

1 Álvarez Junco, 1976. Barrio Alonso, 2015, pp. 255-286.

2 En los años ochenta Pierre Vilar ya había señalado la relación entre «faits de classe» y «faits nationaux»y su interés para la investigación en «Mouvement ouvrier espagnol et questions nationales: quelques réflexions préliminaires», Le Mouvement Social, 128, 1984, pp. 7-14.

3 Anderson, 2008, p. 8. Serrano, 1984. 
Que los conceptos de clase y nación no sean protagonistas del discurso transgresor, individualista e internacionalista del anarquismo, no significa un vacío gnoseológico respecto de dichas categorías, sino, en último extremo, la negación del determinismo que se les atribuye en los procesos de construcción de identidades. La formación identitaria de la clase, reconocida y aceptada por los historiadores sociales de todo el mundo como un proceso de construcción cultural a partir de la experiencia de los actores, desde los trabajos canónicos de E.P. Thompson, nos obliga a incorporar la experiencia de la nación a los análisis sobre la identidad de clase, como agudamente plantea Ferran Archilés, en la medida en que ambas operan de manera similar en relación a los sujetos que son sus actores en sus dos dimensiones básicas, la individual y la colectiva ${ }^{4}$.

La experiencia de nación, como la de patria, alude a realidades que se mueven en diferentes esferas, que utilizan los mismos registros cruzados de arriba a abajo y viceversa, y que caminando en paralelo a los procesos de nacionalización - con o sin los nacionalismos - , tienen una dimensión social insoslayable de la puramente política. Entendida como un proceso complejo que se produce con interacción constante entre sus diferentes planos, y que incumbe tanto al Estado - como agente principal de las iniciativas nacionalizadoras proyectadas, por así decirlo, «desde arriba» hacia la sociedad-, como a las dinámicas que se generan «desde abajo» en los distintos grupos sociales, aceptándolas sumisa y ordenadamente, en unos casos, o desdeñándolas, en otros, desde la apatía y el inmovilismo, parece que ha de ser en la experiencia de nación donde habría que buscar los referentes de esas ideas, no tanto categorías o conceptos, del discurso anarquista sobre la doble identidad clase/nación en España.

El debate sobre la debilidad de la nacionalización española abierto en los años noventa del siglo pasado acaparó el interés de los historiadores ${ }^{5}$ y, quizá, por ello el auge que experimentaron los estudios de las identidades nacionales en España en los últimos años, no alcanzó a la relación anarquismo/nacionalismo ${ }^{6}$. Algo sorprendente, sin embargo, en un país donde el predominio del anarquismo por más tiempo que en otros países del sur de Europa, como Francia o Italia, comprometió, además, el éxito de algunas iniciativas de nacionalización, como señalaba Álvarez Junco,

\footnotetext{
4 Archilés, 2013.

5 De Riquer, 1994. Romeo Mateo, 2011. Bernecker, 2016, Pérez Garzón, 2017.

${ }^{6}$ Sin intención de exhaustividad, véanse Salomón Cheliz, 2011, Smith, 2011, Fernández Gómez, 2013. Véase un enfoque provocador de la cuestión en Díez, 2013.
} 
Ángeles Barrio Alonso

al haber chocado éstas con la indiferencia de las masas, cuando no con su abierta hostilidad al Estado y sus instituciones ${ }^{7}$. La historia de las identidades ha incorporado en los últimos años al análisis de la identidad nacional a la «gente corriente», frente a los otrora habituales estudios centrados en las élites, corroborando el carácter plural y multiforme de la experiencia de la nación analizada en clave social, ya sea a través de la vida cotidiana - en la línea de los sugeridos por Billig como escenarios en su conocida fórmula de «nacionalismo banal» ${ }^{8}-$, o de las emociones capaces de suscitar identidades colectivas que trascienden la jerarquía y el orden social.

Los diferentes imaginarios nacionalistas de la España de los siglos XX y XX, historia, mitos nacionales, género, religión, cine, símbolos, lugares, deporte, música, toros, folklore, etc., han sido analizados desde la perspectiva de la historia cultural de la política, porque las experiencias de nación, como las de clase, se presentan construidas en términos culturales ${ }^{9}$. Contamos, pues, con una cartografía de las culturas políticas en nuestro país en los siglos XIX y XX, mucho más amplia y precisa ${ }^{10}$, y una base sólida para la formulación del proceso de formación «cultural» de la clase obrera en España a través de la relación pueblo/clase. Y no solo como categoría analítica, sino también como realidad social entre 1868 y 1873 , como ya planteara en su momento José María Jover, una relación desarrollada ahora a partir de los estudios sobre republicanismo y obrerismo que confirman que las ideas de nación y patria también operaron en el proceso cultural de formación de clase y en la construcción de los discursos emancipadores de socialistas y anarquistas ${ }^{11}$.

En los textos de los teóricos anarquistas del cambio de siglos aparecen las formulaciones, reformulaciones y re-significaciones de las cosmovisiones y los valores culturales del anarquismo decimonónico, tanto los propios como los compartidos, y fueron un vehículo privilegiado para su divulgación entre las clases populares y trabajadoras, pero de los discursos, como recientemente ha señalado José Álvarez Junco, sólo podemos obtener una idea aproximada del grado de impregnación efectiva de la sociedad en los procesos de nacionalización, que son muy complejos, y en

\footnotetext{
7 Álvarez Junco, 1994.

${ }^{8}$ Billig, 2014.

9 Moreno Luzón; Núñez Seixas, 2013.

10 Pérez Ledesma; Saz, 2013-2016. Pérez Ledesma; Sierra, 2011.

11 Jover, 1976. García Balañá, 2009.
} 
los que se cruzan factores de muy diversa naturaleza ${ }^{12}$. Ponderar el éxito o el fracaso de los proyectos de nacionalización o medir la hostilidad de las clases trabajadoras en la España del cambio de siglos a las tímidas políticas social-reformistas, es un objetivo cuyas dimensiones analíticas desbordan las normas editoriales de esta revista. Aquí, por tanto, nos limitaremos a escrutar la versatilidad y variedad de los discursos anarquistas sobre nación y patria como una herramienta de diagnóstico de la evolución atropellada de ideas y valores que, a partir del 98, inspiraron en el movimiento anarquista nuevas modalidades de acción y movilización en medio de una crisis sin precedentes de la conciencia nacional, y a la que los anarquistas no fueron, precisamente, indiferentes. La prueba es que en la movilización en pro de la nación, el anarquismo se manifestó, primero, a favor del independentismo cubano, como causa justa frente al despotismo de la metrópoli, después, en las peculiares formas de antimilitarismo que adoptó la movilización popular en la Semana Trágica de 1909, o en la controversia que el pacifismo abrió en la comunidad anarquista internacional a raíz de la Gran Guerra, sembrando también la división entre los anarquistas españoles que se manifestaron, como siempre, con vehemencia, defendiendo unos, los menos, pero con voz resonante, la causa aliada, frente a los otros, la mayoría - dispuesta, igualmente, al debatepartidarios de una «pacífica» neutralidad.

La nación - como la patria y, por extensión, los nacionalismos y el patriotismo - era para los anarquistas una realidad concreta, un fenómeno histórico que sintetizaba su crítica al Estado-nación, expresión de su rechazo al Estado, en general, como materialización del dominio de unos hombres sobre otros a lo largo de los siglos. En su Filosofía del anarquismo, publicada en 1889, Charles Malato afirmaba que nación y patria eran la misma cosa, una religión al servicio de los intereses del poder, y de ahí su repulsa a la utilización de los sentimientos patrióticos entre las masas desheredadas. Y ese fue, a grandes rasgos, el discurso oficial del anarquismo internacional pero, como habitualmente sucede en el anarquismo no hay un único discurso, sino varios, y en ellos aparecen tantas evidencias de anti-politicismo y aversión al Estado - tantas que, por sí solas, justificarían el aserto de su negación de la nación y patria y de los sentimientos nacionales y el patriotismo-, como manifestaciones más o menos explícitas de un patriotismo moral, de filiación republicana que,

12 Álvarez Junco, 2016. 
Ángeles Barrio Alonso

en el punto de mayor inflexión de la conciencia crítica nacional tras el 98, adoptaba, incluso, formas regeneracionistas. Junto al discurso de rechazo a la nación española $-\mathrm{y}$ de los nacionalismos y regionalismos de todo tipo-, también hay exaltación de la patria chica, afirmación de la idiosincrasia a través de la lengua y las costumbres, o frialdad, pasividad, e, incluso, rechazo ante lo atávico o tradicional por considerarlo, en muchos casos, anticuado o retrógrado ${ }^{13}$.

La idea de la identidad nacional se presenta en la cultura política anarquista en formas ambivalentes que hacen compatible la negación de la nación como comunidad política (y el nacionalismo, y los nacionalismos, como su producto) con la integración de los ya citados nacionalismos «débiles» como expresión de rebeldía frente a los «fuertes», que representa el Estado-nación. La crítica a las interpretaciones patrióticas de las historias nacionales, especialmente, las de la conquista de América y la acción colonizadora, o la de Marruecos, en algunos teóricos como Anselmo Lorenzo o Ricardo Mella, fue sistemática y rotunda, y la relación del anarquismo con los regionalismos fue, en general, de franca hostilidad, aunque la emergencia de un catalanismo de izquierda aligeró su renuencia a los nacionalismos y regionalismos conservadores y, en un medio ideológicamente permeable como el del anarquismo catalán de aquellos años, se produjeron aproximaciones significativas, hasta, al menos, los años de la Gran Guerra ${ }^{14}$. Porque, del mismo modo que reconocían la identidad española en clave histórica, desde los tiempos pretéritos hasta la aparición del Estado nación, los anarquistas, como veremos, no tuvieron nunca reserva en integrar los sentimientos patrióticos si eran naturales, ni se opusieron a la acepción subjetiva y emocional del patriotismo en la que nación y patria, como comunidad de intereses solidarios, representaban la alternativa a la España «negra», atrasada y clerical.

\section{Los discursos «anti» y «pro» de la nación en el anarquismo}

La cultura política anarquista, no monista por naturaleza, sino diversa y versátil en sus manifestaciones, de discursos «anti» y «pro» característicamente enfáticos y más proclive en sus expresiones a las invocaciones

13 Barrio Alonso, 2016.

14 Gabriel, 2000. Álvarez Junco, 1984. 
y declamaciones que al razonamiento metódico, es el reflejo de las transferencias de sus dos grandes matrices, la de la cultura política liberal, de la que el anarquismo forma parte como uno más de los discursos revolucionarios decimonónicos, y de un internacionalismo obrerista, en competencia permanente con el socialismo de inspiración marxista. Admitiendo que el anarquismo es, como sugiere Murray Bookchin, una especie de ecumenismo anti-autoritario y anti-dogmático ${ }^{15}$, en la cultura política libertaria aparece omnipresente su carácter bifronte, por lo que más que liberal, resulta en la práctica contra-liberal.

El discurso anarquista impugna al Estado como expresión del dominio de unos hombres sobre otros - y en particular al Estado-nación del liberalismo y su jerarquía social-, a sus instituciones y credenciales - soberanía nacional, derechos individuales, sistema representativo, etc.- - y a los valores morales esenciales del liberalismo, como libertad, propiedad, respeto a la ley, dominio político de las mayorías; pero, al tiempo, exalta la soberanía del individuo - la apoteosis de esa soberanía individual, el célebre homo sibi deus hegeliano, el anarquismo la toma de Proudhon, y de Pi y Margall, su traductor en España-, y rechaza la idea de nación y patria, a las que identifica con el Estado y el poder de la burguesía para crear un orden social jerarquizado y profundamente injusto, como el orden liberal, y que es necesario destruir. La conquista del poder político no está, como en el socialismo, entre sus objetivos, y, del mismo modo que impugna el Estado liberal, niega el Estado socialista, deslegitima la organización de partido y la competencia política por lo que supone de subordinación a normas, y de riesgo de legalismo, y, como alternativa al internacionalismo proletario ofrece el cosmopolitismo anarquista que es universalista, en el que el proyecto final de redención del individuo no se reduce al trabajador o a la clase obrera, sino que integra a toda la humanidad.

De todos los discursos de la izquierda, el del anarquismo es el que de forma más vehemente impugna la nación y la patria, y el que se manifiesta más radicalmente contra los sentimientos identitarios que ambas realidades generan, nacionalismo y patriotismo ${ }^{16}$. La nación, como referencia del Estado-nación, es un invento para legalizar el dominio de la burguesía sobre las clases bajas, y, como señalaba Anselmo Lorenzo, haciéndose eco de Mirabeau, el patriotismo un sentimiento exigible única-

15 Bookchin, 2012.

16 Salomón Cheliz, 2011. 
Ángeles Barrio Alonso

mente a los burgueses propietarios, porque «la patria para aquel que nada posee, no es nada» ${ }^{17}$. El patriotismo, «esa virtud suprema del estatismo», según Bakunin ${ }^{18}$, no dejaba de ser, junto con el militarismo, una patraña, un obstáculo más que había que abatir con urgencia en el camino hacia la futura sociedad libertaria. Así lo consideraba Emma Goldman, que vaticinaba tras su final, una especie de epifanía libertaria:

«Cuando hayamos socavado la mentira patriótica, habremos despejado el camino para esa gran construcción en donde todas las nacionalidades se unirán en una hermandad universal, una verdadera sociedad libre.» ${ }^{19}$

La cuestión «nacional» no se plantea nunca en el anarquismo desde la metafísica esencialista de identidades étnicas, lingüísticas o religiosas, sino en términos de conflicto de poder y dominación, con total desinterés por las teorías orgánicas sobre las naciones y las nacionalidades. La nación no preexiste ni trasciende, es una realidad que no requiere explicación porque es concreta y comprobable, y los procesos de construcción de las naciones son, en ese sentido, fenómenos históricos de larga duración, que suceden en el proceso de evolución del poder que, a lo largo de los siglos, adopta la forma del Estado liberal, un producto de las élites burguesas que se resiste a integrar los intereses igualitaristas y democratizadores de las clases bajas. La nación en el discurso anarquista es, en definitiva, un fenómeno histórico, como tantos otros, y la Historia demuestra, siguiendo el discurso de Pi y Margall, cómo «las naciones se hicieron, se deshicieron, se rehicieron y se volvieron a deshacer» ${ }^{20}$.

Sin embargo, el discurso anarquista integra y justifica los nacionalismos periféricos o subestatales, no tanto como expresión de irredentismo - al anarquismo no le interesa especialmente la cuestión del secesionismo, ni las aspiraciones lingüísticas, étnicas o religiosas diferenciales -, sino de rebeldía del débil contra el fuerte, puesto que en el discurso anar-

${ }_{17}$ Véase el capítulo que Anselmo Lorenzo dedica a la patria en El criterio libertario, publicado por primera vez en 1903: Lorenzo, 1977, pp. 39-48.

18 Esta idea está presente en la obra de Bakunin Estatismo y anarquía, Buenos Aires, Anarres, s.f.

19 Goldman, 2010, p. 16.

20 Prólogo de Pi y Margall a la tercera edición de «Las Nacionalidades», Francisco Pí y Margall, Las Nacionalidades, Introducción y Notas: Antoni Jutglar, 1973, p. 74. 
quista el Estado-nación es la encarnación del «fuerte» ${ }^{21}$. Los anarquistas recelan por sistema de las iniciativas de nacionalización que implican al Estado como agente nacionalizador; en el terreno de la educación, por poner un ejemplo representativo, se apartan del modelo de escuela laica y pública del republicanismo, financiada por el Estado y los Ayuntamientos, y proponen, en su lugar, la escuela racionalista y privada; en el de la reforma social y las políticas de trabajo, también rechaza la intervención pública. En 1883, socialistas y anarquistas fueron hostiles, en general, a la Comisión de Reformas Sociales y a la participación en la Información Oral y Escrita ${ }^{22}$; sin embargo, mientras que los socialistas modificaron gradualmente su postura, hasta aceptar, finalmente, en 1904 la colaboración con el Instituto de Reformas Sociales, los anarquistas siguieron manifestándose refractarios, criticando los objetivos del Instituto y rechazando la representación en sus órganos. Su hostilidad a la fórmula de intervencionismo oficial que representaba el Instituto de Reformas Sociales, bajo el auspicio político de Canalejas, y la inspiración filosófica de Azcárate desde su presidencia, revela la falta de apoyos sociales al proyecto de modernización nacional de liberales y republicanos, y demuestra que las iniciativas de nacionalización cuando se ponen en marcha abren procesos que no operan en solitario, sino en relación con los impulsos sociales que se movilizan en pro o en contra de la nación, en unos casos, o en otros, simplemente, se mantienen indiferentes por desconfianza ante las instituciones del Estado ${ }^{23}$.

Los discursos anarquistas, que no son unívocos ni estáticos, se reformulan constantemente para adaptarse a las nuevas realidades, y varían no solo en distintos periodos, en distintas situaciones, o en distintos autores, sino en los mismos periodos, en parecidas circunstancias o, incluso, en un mismo autor se encuentran numerosas diferencias. El antipoliticismo del discurso anarquista no impedía que los anarquistas se sintieran atraídos por la idea de patria del republicanismo, y más concretamente por el componente igualitarista y descentralizador de la idea de nación federal. Su discurso anti-nación iba dirigido contra la nación monárquica, clerical y retrógrada, no contra la patria como comunidad de fraternidad universal a partir de pactos entre individuos libres. Pero la experiencia fracasada de la República federal, trastocó el equilibrio entre el republicanismo y el obre-

21 Beramendi, 2014.

22 De la Calle, 2004.

23 De la Calle, 1989. Palacio Morena, 1988. Carantoña Álvarez; Balado Insunza, 2019. 
Ángeles Barrio Alonso

rismo, el mito de la «república obrera» de los federales se esfumó tras la cantonal, precipitando el proceso de identidad de clase que se impuso sobre otras identidades posibles. Frente al ideal abstracto de la revolución libertaria, que era universal y cosmopolita, la idea de la nación homogénea del republicanismo pasó a ser algo caduco ${ }^{24}$.

Solamente la idea de patria social de los federales sobreviviría en el discurso anarquista a la ruptura de los anarquistas con el partido de Pi y Margall, aunque lo hizo sucesivamente reformulada y en razón de nuevas necesidades y coyunturas políticas ${ }^{25}$. De hecho, fue diluyéndose en el discurso anti-militarista y anti-colonialista que los anarquistas radicalizaron a partir del 98, que ironiza sobre las expectativas militares de una España que, derrotada en Cuba, aún aspira a mantenerse en Marruecos, pero que, al tiempo, se manifiesta «pro» al refutar el discurso de la «meridionalidad» que, desde el darwinismo aplicado a la lucha por la vida entre naciones en el célebre discurso del 4 de mayo de 1898 de Lord Salisbury en el Albert Hall de Londres, situaba a España entre las «naciones moribundas». El discurso patriótico de las elites intelectuales españolas ante las dimensiones del Desastre, el problema español como un problema nacional, que plantearon los miembros de la Generación del 98, no dejó indiferentes a los publicistas anarquistas que también interpretaron el problema en clave «nacional», e, incluso, algunos llegaron a manifestar cierta sensibilidad al nacionalismo emergente de vascos, y, sobre todo, de catalanes que, en medio del pesimismo regeneracionista, comenzaban a movilizarse, en una muestra de insatisfacción e impotencia, contra la ineficiencia y senectud del Estado español ${ }^{26}$.

La humillación sufrida por España en el 98 inspiraba una de las declaraciones anti-militaristas más lúcidas de Ricardo Mella contra el darwinismo social del discurso colonialista británico:

«Señores panegiristas de las naciones poderosas ¿no hay nada más que hacer moral e intelectualmente? ¿no hay algo más de que ocuparse y preocuparse que del esplendor de los ejércitos, de las armadas, de las bancas, los trusts, los feudos industriales? ¿no hay más que la lucha a mordiscos de lobo por una putrefacta tajada?

\footnotetext{
${ }^{24}$ Duarte, 2011. Salomón Chéliz, 2009.

25 Barrio Alonso, 2016.

26 García Carrión, 2015.
} 
Error de la civilización moderna es el culto y fomento de esos factores de aparatosa grandeza que agostan en el alma de las gentes el sentimiento de lo bello, de lo bueno y de lo justo. Error central de los voceros del moderno industrialismo, también culteranos de la fuerza, de olvidar en absoluto que la vida de las naciones brota de abajo, de las capas inferiores, sobre cuya fatigosa labor descansa todo el andamiaje social que sostiene los ejércitos, los monopolios y las grandes y pequeñas factorías. Error central de nuestros tiempos es la preferencia concedida al hombre-mecanismo sobre el hombre-inteligencia, como si toda la evolución humana culminara en un retorno a la bárbara, insolidaria lucha por el pan, de los hombres prehistóricos, recubierta de los oropeles de la civilización.» ${ }^{27}$

No menos crítico se manifestó Mella cuando tuvo conciencia de que el viejo espíritu internacionalista había fenecido arrollado por la abrumadora fuerza de las nacionalidades en la Gran Guerra y, puesto en la tesitura de justificar la aliadofilia de Charles Malato, Jean Grave o el propio Kropotkin, dio rienda suelta a su característico escepticismo sobre la función que la metafísica ejercía en el anarquismo, frente al raciocinio. Mella, como Lorenzo, había sido siempre muy crítico con el nacionalismo y el regionalismo, en agosto de 1909, bajo su habitual seudónimo de «Raúl», había publicado en Tribuna Libre de Gijón un texto demoledor contra el nacionalismo, incluso contra el nacionalismo serbio bendecido por Kropotkin ${ }^{28}$. Sin embargo, seis años después, un análisis desapasionado de los acontecimientos le hizo menos crítico con los anarquistas «disidentes» firmantes del controvertido «Manifiesto de los Dieciséis» - entre ellos, Malato, Grave y Kropotkin, Christian Cornelissen, Enrique Füss... - que después de veinte meses de guerra consideraban que la única solución era responder con toda crudeza a la agresión de Alemania. El semanario Acción Libertaria, que se publicó desde 1910 a 1916, con intermitencias y alternativamente en Gijón, Vigo, Madrid y Gijón, cuando en 1915 la dirección editorial correspondía a Ricardo Mella desde Vigo, lanzó su crítica contra los críticos que condenaban a los disidentes acusándolos de «politización», de «aburguesamiento», de traición al ideal libertario de la paz universal:

27 «Error central del poderío de las naciones», artículo firmado por Ricardo Mella en Acción Libertaria, Madrid, 6 de junio de 1912.

28 Barrio Alonso, 2015. 
Ángeles Barrio Alonso

«No obstante el optimismo general que suponía imposible una guerra entre las grandes naciones europeas, hubo siempre entre nosotros espíritus sagaces cuya visión del peligro les llevó a especializarse en el estudio de las más espinosas cuestiones internacionales (...) El alerta se dio desde diversas partes y desde diversos países, Jaurès entre los socialistas, Kropotkin entre los nuestros, sin excluir tampoco a algunos representantes de la socialdemocracia y del anarquismo alemanes (...).

Penoso es reconocer la propia impotencia y nada positivo pudo ser realizado. En teoría había acuerdo entre los anarquistas, también entre los sindicalistas revolucionarios, más ni unos ni otros pudieron acordar voluntades por la potísima razón de estar en minoría en la Internacional proletaria...» 29

Mella proponía: si Francia había hecho de la máxima «un pueblo unido hasta la muerte en la defensa de una causa justa» la razón para mantener vivo el legado histórico de la Revolución, por qué resistirse en España al objetivo de una Europa en paz, con nuevas formas de convivencia social más llevaderas; por qué no soñar, incluso, con que España pudiera llegar a tener su «1789», o mejor aún, su «1793».

\section{Historicismo, evolucionismo y nación española}

El discurso anarquista no fue inmune al efecto que en el pensamiento liberal produjo la irrupción del positivismo y el evolucionismo en un país de mayoría católica, como España. Aunque las nuevas teorías científicas habían penetrado unos años antes, la controversia sobre el evolucionismo no se divulgó hasta que las libertades del Sexenio Democrático propiciaron el ambiente favorable para ello. El evolucionismo que, como el positivismo, llegó a España a través de Francia y se llamó transformismo, trasladaba la teoría de la lucha por la vida y la selección de las especies desde la biología a las ciencias sociales, la evolución tomaba cuerpo en el proceso histórico, desde la época primitiva a lo largo de los tiempos, como un continuum, en una secuencia de fenómenos sucesivos que constituían la historia de la humanidad, y en esa secuencia era donde el anarquismo situaba el nacimiento de las naciones como un fenómeno histórico más. Al introducir la cuestión de la lucha por la existencia en la teoría gene-

\footnotetext{
${ }^{29}$ Acción Libertaria, Gijón, 4 de junio de 1915.
} 
ral de la evolución de las especies, desde la biología a la ciencia social, el evolucionismo ofrecía a las burguesías liberales de todo el mundo un argumento científico para justificar su dominio social, según el principio de «los mejores» o los «más aptos» ${ }^{30}$. Aunque el acuerdo sobre estos extremos fue imposible por la falta de base empírica para demostrar que el dominio de la burguesía se debía a sus cualidades innatas de excelencia, el llamado darwinismo social - una interpretación sesgada de la teoría de Darwin - fue, probablemente, el debate más importante de esos años que, aplicado a la competencia entre naciones, se convirtió en la filosofía legitimadora del poder de unas naciones sobre otras, una filosofía que en España, tras el 98, alimentó la crisis de la conciencia nacional.

La lectura que en el anarquismo se hizo de la experiencia del Desastre se inscribe en la crisis de fin de siglo, en el sentimiento de incertidumbre generalizada ante el cambio y las demandas de la sociedad de masas, en la que quedaba atrás el individualismo fichteano, característico del anarquismo primitivo que re-significaba su discurso reformulándolo en clave social, dando paso al anarquismo social y societario, característico del anarquismo del siglo $\mathrm{XX}^{31}$. Los anarquistas refutaban la metafísica idealista por acientífica e inútil para la sociedad industrial, pero el compromiso del anarquismo con el positivismo se redujo, en la práctica, al rechazo de la intromisión de la religión en la ciencia, y de hecho, la idea de la historia que predomina en el discurso anarquista de esos años es la de la evolución. Que la ciencia se utilizara como refuerzo de la ideología, que el conocimiento científico no se pusiera al servicio de los valores universales de justicia, sino al del poder, era motivo suficiente para que los anarquistas, que se rendían ante el progreso y la técnica, fueran reticentes a lo que denominaban «ciencia burguesa», en oposición a la «ciencia obrera», en una alusión clara al debate entre Darwin y Lamarck acerca de la «buena y la mala ciencia». Así de claro se expresaba Anselmo Lorenzo en su obra El Pueblo:

«la ciencia obrera toma de la ciencia burguesa lo que contiene de verdadera ciencia, pero desecha los sofismas que sirven de base al privilegio, y con criterio despreocupado agrupa conocimientos que sirven para beneficiar a todos los hombres y para impedir que los mixtificadores puedan privar a los trabajadores de sus derechos naturales y arrebatarles el fruto de su trabajo.

30 Girón Sierra, 2005.

31 Barrio Alonso, 2018. 
Ángeles Barrio Alonso

Y mientras los sabios discuten si hay o no criterio de verdad, los trabajadores para adquirir la verdad con el brillante prestigio de la evidencia, tenemos un criterio de justicia que los privilegiados no pueden tener sino cuando por excepción reniegan del privilegio, lo abandonan y lo desprecian...» 32

A los anarquistas el rigor metodológico, el escrúpulo empirista del positivismo, les interesaba mucho menos que la controversia sobre el evolucionismo como motor de la historia, y de ahí que interpretaran la formación de las naciones dentro del proceso evolutivo, como una sucesión de fases en razón de causas físicas y morales que implicaban no a la nación, sino a toda la humanidad. Para los anarquistas, el punto de ruptura en el continuum que suponía el proceso general de la evolución, no era la nación, sino la revolución. Evolución y revolución como procesos consecutivos y complementarios, suponían un factor novedoso que modificaba la noción de revolución en el anarquismo anterior al fin de siglo, llevándola al terreno de las realidades materiales, equiparable al de los fenómenos físicos. La certeza acerca de la inminencia de la revolución, un acontecimiento de magnitud planetaria que alumbraría la sociedad futura, da una idea aproximada del impacto real de las teorías evolucionistas entre los teóricos anarquistas en esos años del fin de siglo. En la relación establecida entre la biología y la ciencia social, tal como se deducía de la lectura de Eliseo Reclùs en Evolución, revolución y anarquismo ${ }^{33}$, la revolución podía ser interpretada en términos no utópicos sino historicistas, como un acontecimiento que, si bien sus objetivos estaban formulados en clave universal, su realización no eludía las referencias «nacionales» como fuente de unas causas ineludibles en su planteamiento y organización. Ante tal desafío argumental, los anarquistas centraron su interés en presentar a la revolución como un hecho sucesivo a la evolución. De la noción de revolución abstracta e inconcreta del pasado, la revolución, ahora presentida, aparecía descrita en los textos como un fenómeno real que habría de suceder, no en un tiempo y un espacio indeterminados, sino en contextos reales, en situaciones concretas, previsiblemente «nacionales». La revolución, en definitiva, no se produciría en el terreno de lo imaginario, sino en países y contextos nacionales determinados, como un episodio inexorable dentro del proceso histórico ${ }^{34}$.

\footnotetext{
32 Anselmo Lorenzo El pueblo. Estudio libertario, Sempere, Valencia s.f. p. 41.

33 Reclus, 1969.

34 Barrio Alonso, 2014.
} 
Las referencias de la idea de nación y patria de los anarquistas españoles en el siglo XIX fueron las del republicanismo, y no hubo otro discurso dominante que no fuera el de la nación española, como se ha señalado con anterioridad. No obstante, tampoco el republicanismo había formulado un discurso homogéneo sobre la nación, sus diferentes tradiciones en las que la idea de nación jugaba un papel esencial para la formulación del poder y la organización del Estado, dieron lugar a que dentro de cada una de las familias republicanas se hicieran evidentes las variaciones filosóficas del discurso matriz revolucionario que les servía de inspiración. La diferencia entre la idea de nación liberal como producto de la voluntad mayoritaria de ciudadanos, de la que obtenía su legitimidad para constituir un determinado sistema político, y la de la nación como comunidad específica, ya fuera étnica, lingüística o religiosa, que preexistía a su constitución formal y existía al margen de la política, la economía y la sociedad, no era únicamente filosófica, sino una referencia esencial, un principio, que condicionaba las propuestas políticas que se derivaban de ambas nociones. Por la proximidad del anarquismo al federalismo, y como ala izquierda del republicanismo, éste fue el que rindió más referentes al discurso anarquista en su crítica al Estado-nación pero, a pesar del núcleo ideológico común que compartieron todos los discursos federalistas, sus variaciones también se correspondían con las corrientes internas -individualistas, pactistas, etc.- $-\mathrm{y}$, como los del anarquismo, no fueron estáticos. El programa federal, aplicado a la realidad española, evolucionó a partir del Sexenio, y especialmente, tras la experiencia fracasada de la República, en las distintas direcciones a las que apuntaban sus propias corrientes internas dando variedad a su discurso sobre la nación. Los casos de Castelar, con su federalismo fugaz que se hizo centralismo puro a partir de 1873, de Salmerón, cuyo federalismo organicista de matriz krausista se reafirmaría, tras el 98, en un patriotismo cívico, democrático y modernizador, o el de Pi y Margall, que reconociendo la antigüedad de la nación española en la unificación de los Reyes Católicos, consideraba que ésta no alcanzaría su plenitud más que en el federalismo y en la descentralización, demuestran la versatilidad de las acepciones de la nación entre los republicanos, bajo la misma creencia en la existencia de una nación española, construida históricamente antes de las revoluciones liberales ${ }^{35}$.

35 Beramendi, 2012. Suárez Cortina; Ridolfi, 2013. 
Ángeles Barrio Alonso

La fuente principal de la que bebieron los anarquistas no sólo para la idea de nación, sino también, y sobre todo, para la descentralización y el pacto federativo, fue sin duda alguna Pi y Margall que en Las Nacionalidades se situaba muy lejos del Castelar que, escarmentado de la República, defendía un nacionalismo español puro y centralista, o, incluso, del Salmerón que clamaba, contra la decadencia de España, por una nación libre, civilizada y moderna compatible únicamente con la república, que entendía la nación como el resultado de un grupo humano - pueblono sometido a poder ajeno, una realidad ni trascendente ni irreversible, sino que surgía formalmente con las revoluciones liberales, que dependía de la voluntad de asociación libre de los individuos. En el caso de la nación española, cuya existencia Pi y Margall no ponía en duda, su historia le proporcionaba numerosos argumentos a favor del federalismo y la descentralización. De las consideraciones sobre la descentralización de Pi y Margall, que seguía siendo una referencia moral para los anarquistas de fin de siglo - la encendida necrológica que, apenas unas semanas después de su muerte, le dedicó en uno de sus primeros números el periódico $L a$ Huelga General, financiado por Ferrer Guardia, tratándolo como el «primer anarquista» era sólo una prueba más ${ }^{36}-$, tomaron los anarquistas sus ideas centrales para su noción de patria social y federal.

Sin embargo, la distancia entre las clases populares, después del fracaso de la República federal, y el partido federal, se había hecho progresivamente grande y se hacía evidente entre la comunidad libertaria. En términos evolucionistas, Anselmo Lorenzo la interpretaba como el resultado de una práctica política por parte del republicanismo que, por más que los federales se empeñaran en darle sentido social, era una simple variante del principio autoritario acreditado en las prácticas políticas de otras naciones no monárquicas, sino republicanas:

«Quieren los republicanos que, aceptando la ley de la evolución tal como sus sabios la definen, esperen pacientemente los trabajadores a que se decrete el momento oportuno de que los desheredados dejen de serlo, y como esa oportunidad no se presentará nunca, los hijos del privilegio siempre tendrán ocasión de alcanzar las posiciones sociales ventajosas, de ofrecerse a la admiración de las muchedumbres, y nosotros, pobres desheredados, o más bien despojados de nuestra participación en la herencia social, siempre seremos, como individuos, pobres trabajadores que

${ }^{36}$ La Huelga General, Barcelona, 5 de diciembre de 1901. 
se consumen en la ignorancia y las privaciones, y colectivamente, en el lenguaje político, cuando convenga adularnos, el pueblo, y cuando crean prudente dirigirnos alguna censura, las masas inconscientes.» ${ }^{37}$

La idea de revolución aparece formulada en el discurso anarquista como un momento fatal, pero necesario, porque formaba parte de un proceso general, en el que, si como en el ciclo de la naturaleza evolución y medio eran factores determinantes, habría que modificar el medio para que las revoluciones de la naturaleza tuvieran su correlato en la sociedad. En una conferencia que Ricardo Mella pronuncio en el Círculo Federal de Vigo en 1891, con el título «Evolución y revolución», el proceso se razonaba así:

«Soy, pues, revolucionario, porque soy evolucionista: quiero la evolución con todas sus consecuencias, quiero que la revolución modifique sustancialmente las condiciones del presente.» ${ }^{38}$

De la idea de revolución subsidiaria del republicanismo de los tiempos pasados, basada en la conspiración y el motín, con participación del ejército, barricadas en las calles y alianzas de clase, se había llegado ahora a una idea de revolución en un proceso histórico de conclusión inexorable, como transformación radical de la realidad. Nada tenía que ver la revolución de la que hablaba Mella en 1891 con la de Castelar de 1870, apenas sugerida en el prólogo escrito a Historia de las clases trabajadoras de Fernando Garrido, entre referencias abstractas de progreso, como la simple mejora del «cuarto estado»:

«No, no caerá la propiedad individual, raíz de todas las libertades individuales, no, no se establecerá el comunismo, reacción absurda a los tiempos de las tribus asiáticas; pero por sabias combinaciones de libertad, tan fecunda como la misma naturaleza, se mejorarán las condiciones sociales del cuarto estado, del pueblo. Esta es mi profunda convicción, esta es la convicción de todos los amantes del progreso humano.» ${ }^{39}$

37 Anselmo Lorenzo Acracia o República, Refutación al discurso pronunciado por D. Luis Carreras el día 20 de febrero de 1886 en la fiesta del Círculo Democrático Federal Instructivo de Sabadell, Imprenta y Litografía de Juan Comas y Faura, Sabadell 1886, p. 24.

38 «Evolución y revolución», conferencia pronunciada por Ricardo Mella en el Círculo Federal de Vigo en 1891, recogida en Ricardo Mella, Forjando un mundo libre, La Piqueta, Madrid 1977, pp. 65-75.

39 Garrido, 1970, Vol. I. pág. XIV. 
Ángeles Barrio Alonso

En la cultura política republicana, los republicanos unitarios, como los federales, se consideraban agentes de nacionalización, el proyecto republicano era «nacional» $\mathrm{y}$ «nacionalizador»; pero también era insurreccional, algo muy atractivo para el anarquismo ${ }^{40}$. Desde la práctica insurreccional, los federales le habían dado a la «junta» el valor de célula local en su proyecto político, una noción que los anarquistas adaptaron fácilmente a la fórmula de comuna, como expresión de la gran obra de descentralización que implicaba el federalismo. El sujeto de la nación imaginada en el mito de la «república obrera» de los federales no era la burguesía sino las clases jornaleras que encarnaban la autonomía colectiva de la nación. Tanto en Castelar, como en Pí y Margall, de forma más clara, había una idea de nación como emancipación, de la que el anarquismo tomo la noción de «pueblo» - el pueblo trabajador de los federales - para hacerla suya bajo la fórmula de «proletariado militante» - la que adopta Anselmo Lorenzo en su libro, cuyo subtítulo era «Memorias de un internacionalista»-, en su viaje desde el individualismo hacia el societarismo, un elemento fundamental para construir su propia cultura política libertaria dentro del obrerismo organizado. Como ha puesto de manifiesto Albert García Balañá en sus trabajos sobre política y trabajo en la industria textil catalana en el último cuarto del siglo XIX, el proceso de transformación del otrora «pueblo» en «clase», fue una experiencia «plebeya» de proletarización ${ }^{41}$, en la que se escenifica la ruptura del obrerismo internacionalista con el partido federal, pero no con muchos de sus valores, profundamente arraigados entre las clases populares y trabajadoras, algunos de los cuales se mantuvieran vivos en el anarquismo hasta, al menos, los años treinta del siglo XX.

La derrota de la República federal penalizó a los anarquistas doblemente porque, además, los socialistas, contrarios al cantonalismo, los responsabilizaron del fracaso, aunque había constancia de que su participación en la cantonal había sido limitada y que el liderazgo de la insurrección había correspondido a los federales intransigentes. Para los socialistas España era, como para los anarquistas, una realidad histórica y cultural cuyas referencias no requerían justificaciones ni argumentos, la nación existía y no era necesario explicarla ${ }^{42}$. Las naciones como abstracción eran sólo el soporte sobre el que se construían los relatos nacionalistas, y de ahí que socialistas y anarquistas hablaran de España como

\footnotetext{
40 Duarte, 2015.

41 García Balañá, 2004, 2008, y 2009.

42 Forcadell, 2009.
} 
«nuestra nación», se refirieran a «los españoles», y reflexionaran sobre «España», porque ya fuera en términos líricos de exaltación patriótica, o en términos vergonzantes, la nación era una realidad que podía ser atrasada e injusta, pero el sentimiento patriótico si era natural, significaba la solidaridad con el pueblo con el que se comparte la existencia. Así, cuando en 1910 llegó el momento de dar nombre a una nueva formación sindical de carácter nacional, en la duda de llamarla, como en Francia Confédération Générale du Travail, o como en Italia Confederazione Generale del Lavoro, los anarquistas españoles terminaron llamándola Confederación Nacional de Trabajo, CNT.

En el terreno lingüístico tampoco hubo grandes disquisiciones entre los anarquistas, partidarios del esperanto como idioma de fraternidad universal, mientras que, sólo de forma excepcional, algunos antepusieron al castellano la defensa de las lenguas maternas. En el caso de Jaume Brossa hubo una tímida defensa del catalán en la Revista Blanca en los primeros años del siglo, y por las mismas fechas, en el caso de Josep Mas Gomeri, hubo una reivindicación del regionalismo en El Porvenir del Obrero de Mahón, como una forma evolucionada del antiguo federalismo acorde a los cambios y a las nuevas necesidades, que destacaba frente a la hostilidad generalizada de la prensa anarquista a los regionalismos. Pero, en definitiva, no pasaron de ser casos relativamente aislados en medio del característico eclecticismo anarquista que integraba por igual a los defensores del particularismo lingüístico y antropológico y a los renuentes a la utilización de la lengua materna, tradiciones y tópicos idiosincrásicos en sus textos. Los publicistas y editores catalanes Federico Urales y Soledad Gustavo - Juan Montseny y Teresa Mañé, padres de Federica Montseny - son un buen exponente de esa especie de sincretismo, no solo en los textos publicados en la Revista Blanca, sino, en general, en la línea que mantuvo la empresa editorial de la familia ${ }^{43}$.

\section{La moralidad o inmoralidad del sentimiento patriótico}

En la Internacional primitiva ya se había afirmado el discurso del internacionalismo proletario frente al del nacionalismo español, lo que incluía el rechazo al patriotismo. Para los bakuninistas, que, inicialmente,

43 Gabriel, 2000. 
Ángeles Barrio Alonso

no eran mayoría en ella, la nación era, desde el derecho de gentes, un concepto de uso político, de finalidad política, no un ente orgánico, por mucho que los krausistas pretendieran justificar este extremo desde el historicismo. En los años de mayor auge de la Internacional española, los bakuninistas fueron, por tanto, oficialmente los únicos antipatriotas y, frente al republicanismo, reivindicaron no la soberanía nacional, sino la soberanía del pueblo, entendido el pueblo como humanidad, en sentido amplio, ya que la categoría pueblo/trabajador no fue acuñada hasta unos años más tarde, cuando la ruptura con el republicanismo se había consumado. Para los anarquistas, la patria, como la nación, era un invento de la burguesía y sus connotaciones de nacionalidad la hacían identificable con el Estado, con la opresión; la patria era, en definitiva, un recurso del poder que, a través del sentimiento patriótico, justificaba expediciones armadas y legalizaba de forma hipócrita la violencia:

«La nación no es más que el Estado camuflado para dominar y legislar impunemente en determinada área geográfica, mientras una guerra o cualquier otra causa convencional no altere las fronteras históricas establecidas en otra guerra.» ${ }^{44}$

Pero los anarquistas eran, al mismo tiempo, conscientes de que la idea de comunidad podía estimular o frenar, según los casos, el sentimiento patriótico que impulsaba las guerras, y no el que se ponía al servicio del bienestar colectivo. Como hemos visto, la idea de nación como comunidad de hábitos no era execrable para los anarquistas, sino la de nación como comunidad de intereses, ya que no había lazos que pudieran unir los intereses del proletariado con los del gran capital, ni justificación moral alguna para que, apelando a la idea de comunidad nacional a partir de la tradición y la historia - en alusión a las historias nacionales liberales se pusiera al servicio de los intereses de la burguesía. Desde, al menos, la Comuna de París - que para los trabajadores franceses era un episodio nacional glorioso, mientras que para la burguesía era, simplemente, un suceso salvaje-, el discurso anarquista cuestionó las interpretaciones que hacían de la burguesía el sujeto histórico en exclusiva de la modernidad y el progreso, en detrimento de las clases populares y trabajadoras. En Ricardo Mella aparece la crítica a la interpretación sesgada que la tradición liberal había hecho de la revolución, convirtiéndola en bandera de privile-

44 Alaiz, 1993, p. 48. 
gios de clase, al mismo tiempo que la denuncia de las bajas pasiones escondidas tras la defensa de la patria:

«No es por la historia, por la tradición, por las cualidades y condiciones privativas de cada personalidad como se ha de establecer el derecho a la autonomía o a la independencia. Colocarse en ese terreno es pasarse al enemigo, caer de bruces en el terreno del adversario, de los hombres de la tradición, defensores de los privilegios pasados, presentes y futuros en lo político, lo económico y lo social.

La autonomía, la libertad de gobernarse, mejor, de arreglar sus asuntos por sí mismos, ya se trate de individuos, ya de colectividades, es un derecho natural, primitivo, anterior y superior a toda ley, de tal modo que cualquier restricción lo anula en absoluto. Reducirlo a la existencia de las pequeñas nacionalidades es suprimir de un plumazo todo el progreso y olvidar por completo el problema universal de la emancipación humana.» ${ }^{45}$

Desde la moralidad estricta anarquista, el sentimiento patriótico solo se legitimaba si contribuía a la unidad de los pueblos, a la armonía y la justicia universal. La guerra es siempre injustificable en el discurso anarquista que, como alternativa frente al sentimiento nacional patriótico agresivo, ofrecía el fomento del sentimiento de amor a la humanidad, la solidaridad. Y, como siempre, con alusiones a un derecho natural, anterior y superior a toda ley, como insistía Mella, y como fuente del derecho al autogobierno de individuos y colectividades, el cosmopolitismo característico del discurso anarquista funcionaba como superación de la patria, ya fuera ésta la grande o la chica. No en vano, unos años después, Felipe Alaiz cuestionaba el concepto unívoco de «españolidad» en su obra $\mathrm{Ha}$ cia una federación de autonomías ibérica, bajo un epígrafe significativo: «Las ideas universales y el pensamiento español» ${ }^{46}$.

Fuera de la esfera del poder que vinculaba inexorablemente a la nación y a la patria con el Estado, el anarquismo era permisivo con el principio de autodeterminación de las naciones, siempre que estuviera basado en el respeto mutuo y aceptase sin restricciones la diversidad. De ese nacionalismo tolerante pero suspicaz al particularismo extremo y al fanatismo, el discurso anarquista deducía un patriotismo profundamente social y reactivo contra

45 Mella, 1978,pp. 257-258.

46 Alaiz, 1993, véanse especialmente las páginas 468 y siguientes en que trata este aspecto. 
Ángeles Barrio Alonso

el estigma de la España negra, contra los prejuicios y las imágenes negativas de España en el extranjero. La experiencia de de ese sentimiento de patriotismo moral de Anselmo Lorenzo, furibundamente anti-nacionalista, narrada por él mismo resulta ilustrativa. Estando viviendo por un tiempo en Francia, adonde se había trasladado para divulgar la Internacional, a Anselmo Lorenzo no le había intimidado la política de excepción contra la Comuna, siendo como era un trabajador extranjero. Quizá por ello sus compañeros de trabajo que, a pesar de su total extrañeza ante la diferencia de costumbres con los franceses y totalmente convencidos del atraso español, le consideraron un español excepcional. De ahí que, cuando se proclamó la Primera República en España, se viera obligado a aclararles algunos extremos para desterrar los tópicos que la literatura francesa había divulgado sobre las costumbres supuestamente «bárbaras» de los españoles:

«Un día trabajando en las obras de la imprenta del Semaphore, me distraía en mi trabajo tarareando el gran coro de Los Hugonotes, y fui a componer una frase a la caja en cursiva; a la misma se acercó otro compañero y fue tal su admiración de que entonara aquel fragmento musical un español, que me preguntó:

¿Dónde ha aprendido usted esa música?

En Madrid, le respondí

Pues qué ¿hay opera en Madrid?.

Mi respuesta afirmativa no le convenció; recurrió a los otros compañeros para que le ayudaran a sostener que en España no se toca, canta, baila más que el bolero, porque así lo decía no se que autor que había recorrido España, confirmado por Gustavo Doré (...). En vano les dije que todo aquello era falso; que sus escritores les adulaban y engañaban; que tocante a la opera, mientras en Marsella había un gran teatro que no puede funcionar sin subvención del Ayuntamiento y presenta ópera italiana con letra francesa, en Barcelona hay casi constantemente opera con letra italiana y excelentes compañías en el Liceo (...).» ${ }^{47}$

Después del 98, el discurso dominante en el anarquismo fue el de redención moral del pueblo español, que trataba de rescatar de la historia las cualidades de la sociedad española, virtudes que se concretaban en el pueblo, que es, naturalmente, honrado, noble y valeroso. El discurso de la nación española de los anarquistas basculó en esos años entre el progreso y la civilización, oponiendo a la idea de una España libre y civilizada - la Es-

47 Anselmo Lorenzo, El proletariado militante, Valencia, Sempere, s.f. pp. 314-315. 
paña a que aspiraban los anarquistas - , la de una España reaccionaria y clerical que, desafortunadamente, era la más difundida fuera de nuestras fronteras. En el proceso de Montjuich en 1897 ya se había puesto de manifiesto agitando el fantasma de La Mano Negra, como exponente de la corrupción crónica por parte de las autoridades y de la injusticia del sistema. En la Semana Trágica en julio de1909, en el procesamiento de Ferrer Guardia y su ejecución en octubre de ese mismo año, o en la campaña del «Maura no!», los anarquistas siempre estuvieron contra la España «negra» y clerical.

De ello trataba Ricardo Mella - menos cáustico que Lorenzo contra los nacionalismos, pero igual de crítico con las estériles peleas «burguesas» entre castellanistas, catalanistas, bizcaitarras o galleguistas-, en un artículo titulado «Las dos Españas», publicado en La Protesta de Buenos Aires en octubre de 1909, que alcanzo cierta resonancia y que comenzaba con un rotundo «no voy a hablar, naturalmente, a título de patriota...», para abundar, sin embargo, a renglón seguido en la refutación de la leyenda negra española desde una desapasionada interpretación de la realidad española, comparándola con la de Francia, Italia, Gran Bretaña o Estados Unidos:

«Anda por ahí una leyenda que nos pinta como país absolutamente ignorante, degenerado por la tauromaquia y el flamenquismo, sometidos servilmente a la mas dura tiranía, atenazados por el atavismo inquisitorial. Aquí por lo visto llevan las mujeres la navaja en la liga, perdura el derecho de pernada, subsisten los señores feudales y la sopa de convento, se mata el hambre arañando rabiosamente las cuerdas de una guitarra, y entre cañas y toros y juergas y rezos, el pueblo español está tan embrutecido hogaño como antaño. Los demás países de Europa nos miran como bichos raros y nosotros mismos parecemos complacidos de que se nos tenga por anacrónicos.»

(...)

Las leyes de represión del anarquismo son en España copia de las francesas, como los destierros actuales son una pésima traducción del domicilio coatto de Italia. Si aquí tenemos tormentos de Montjuich, la muy republicana y federal América del norte tiene las horcas de Chicago; su expulsión de anarquistas la muy libre Argentina. (...)

Políticamente, la España actual, la otra España ajena al oficialismo, distinta y opuesta al Estado, contraria a la frailocracia, nuestra mayor calamidad, reñida del todo con la tradición de la que la leyenda arranca, es quizá menos conocida que la España social. Esta otra España es la del federalismo insurgente, del socialismo y el anarquismo activos, una España de ideas netamente progresivas, fautora, no simple recipiente de ideales y aspiraciones generosas. Esta otra España es la de centena- 
Ángeles Barrio Alonso

res de escuelas neutras, clausuradas ahora por la reacción (...), es la de la gran obra de educación y cultura que revela la existencia de un pueblo capaz de todas las empresas (...). El alzamiento de Cataluña entera, más algunas ciudades del resto de España, contra la acción militar en Melilla, caso no igualado hasta el día ¿no demuestra, con hechos, que la España de la leyenda es una España falsa, amasada con convencionalismos y mentiras negras y rojas? (...).»

Pero, como correspondía al discurso de un teórico anarquista y no de un escritor liberal o filo-republicano, Mella ponía el énfasis en la transformación de la sociedad, en la revolución como un proceso intensivo de regeneración del individuo y la colectividad. Espoleado por la conflictividad, el discurso «anti» del anarquismo, se hacía radical contra el Estado, pero también en la frustración y el escepticismo respecto de los políticos y la clase dirigente, donde Ricardo Mella, una vez más, se mostraba tan regeneracionista como libertario:

«Unos cuantos afamados periodistas no cesan de batir el parche clamando por el resurgimiento de España. Las principales empresas periodísticas y talentudos corresponsales que cumplen su patriótica misión señalándonos el florido camino por donde los grandes pueblos van hacia la fortuna y la dicha (...). Con el celo de la sangre africana, que dicen que tenemos, andamos presurosos en corresponder a los nobles esfuerzos de nuestros más preclaros intelectuales. España renace.

¿Renace? (...)

El renacer de España podría venir tan pronto como su majestad el capital se diera a partido reconociendo que con salarios de una, dos y tres pesetas no puede haber obreros hábiles, fuertes, obreros inteligentes; que con jornales de diez, doce y más horas no puede haber producción esmerada, regular y remuneradora, que con ganancias de avaro no puede haber esplendidos compradores; que con rutinas de práctica ramplona no puede haber adelantos industriales; que con petulancias librescas no puede haber aciertos técnicos, no perfeccionamientos ni invenciones (...). El renacer de España podría comenzar el día mismo en que las clases medias dejaran de espantarse ridículamente de las agitaciones obreras; dejaran de asustarse a la sola presencia de quien quiera decirse revolucionario, socialista, sindicalista o anarquista; dejaran de vivir en la santa ignorancia de todo lo que es ideología y pasión y amor abnegado por las cosas que afectan a todos los hombres, cualquiera que sea su raza, color o condición...» ${ }^{48}$

${ }^{48}$ El libertario, Gijón, 9 de noviembre de 1912. 
Para los anarquistas no había otra patria que la social y federal, la de las tradiciones «culturales» compartidas con la izquierda liberal y jacobina del viejo republicanismo, unas tradiciones que en Cataluña venían de antiguo y gozaban de un arraigo entre las clases populares mayor que en otros zonas de España, como Andalucía, Asturias, Valencia, Zaragoza o Galicia, donde el anarquismo no dejaría de crecer en los años del cambio de siglos pero, al igual que en Cataluña, como un movimiento autónomo e independiente, libre de los antiguos vínculos ideológicos y de partido con el republicanismo, y orientado a la lucha sindical. De ahí que sus discursos, con el tiempo, solo fueran compatibles con los de los nacionalistas de izquierda, como fue en el caso de Esquerra Republicana de Cataluña, y no con los nacionalistas vascos, por ejemplo. La relación de Salvador Seguí y Joan Peiró - dos de los líderes más carismáticos del sector «moderado» de la CNT - con Françesc Layret y Lluis Companys en los años veinte y treinta, en un escenario ya muy distinto al de entre-siglos, iba más allá del anarquismo filosófico o de las discusiones teóricas sobre el papel del sindicalismo en el anarquismo. Por ello, y con independencia de que sus raíces fueran las de una tradición de rebeldía, característica específica del anarquismo catalán, como sostiene Xavier Díez ${ }^{49}$, esa relación entre sindicalistas y catalanistas de izquierda sólo era posible en el marco de un proyecto político transformador, y no de una afirmación nacionalista, lingüística o artística.

\section{Bibliografia}

AlaIz, Felipe, Hacia una federación de autonomías ibérica.Madrid, Madre Tierra/Fundación Anselmo Lorenzo, 1993.

ÁlvAREZ JunCO, José, La ideología política del anarquismo español, 1868-1919, Madrid, Siglo XXI, 1976.

Álvarez JunCO, José, «Les anarchistes face au nationalisme catalán (18081910)», Le Mouvement Social, 128 (1984), pp. 43-58.

ÁlvareZ JunCo, José, «Movimientos sociales en España: del modelo tradicional a la modernidad postfranquista», en Enrique LARAÑA, Joseph GUSFIELD (eds.), Los nuevos movimientos sociales. De la ideología a la identidad, Madrid, CIS, 1994, pp. 413-442.

49 Díez, 2013.

https://doi.org/10.1387/hc.21236 
Ángeles Barrio Alonso

Álvarez Junco, José, Dioses útiles. Naciones y nacionalismos, Madrid, Galaxia Gutenberg, 2016.

ANDERSON, Benedict, Bajo tres banderas. Anarquismo e imaginación anticolonial, Madrid, Akal, 2008.

ARCHILÉS, Ferran, «Lenguajes de nación. Las «experiencias de nación» y los procesos de nacionalización: propuestas para un debate», Ayer, 90 (2013), pp. 91-114.

BAKUnIn, Mijail, Estatismo y anarquía, Anarres, Buenos Aires, s.f.

BARRIo Alonso, Ángeles, «Elites revolucionarias y liderazgo en el discurso anarquista en España y México, 1860-1936», en Evelia TrEjo EsTRADA, Aurora Cano Andaluz, Manuel Suárez Cortina (eds.), Elites en México y España. Estudios sobre política y cultura. México DF, UNAM, 2014, pp. 267-294.

BARRIO Alonso, Ángeles, «Cultura política libertaria», en Carlos ForCADELL, Manuel SuÁrez CORTINA (eds), La Restauración y la República, 1874-1936, vol. III, Historia de las culturas políticas en España y América Latina, Madrid, Marcial Pons, Prensas Universitarias de Zaragoza, 2015, pp. 255-286.

Barrio Alonso, Ángeles, Ricardo Mella: frustraciones federales y expectativas libertarias de un idealista tranquilo.Santander, Editorial Universidad de Cantabria, 2015.

BARrio Alonso, Ángeles, «Libertad, solidaridad y autogestión en el federalismo libertario», en Manuel SuÁrez Cortina (ed.) Federalismos. Europa del Sur y América Latina en perspectiva histórica. Granada, Comares, 2016, pp. 165-215.

BARrio AlOnso, Ángeles, «The Making of the English Working Class, 50 años después. Su legado para la historia obrera», en Julián SANZ, José B ABIANO, Francisco ErICE (eds.), E.P. Thompson. Marxismo e historia social, Madrid, Siglo XXI, 2016, pp. 79-113.

BARrio Alonso, Ángeles, «Las metamorfosis del anarquismo y sus discursos sobre evolución y revolución en el fin de siglo en España y México», en Aurora Cano Andaluz, Evelia Trejo Estrada, Manuel Suárez Cortina (eds.), Escenarios de culturas entre dos siglos. España y México 1880-1920, Ciudad de México, UNAM, 2018, pp. 180-213.

BARrio Alonso, Ángeles, «Reforma social, nacionalización (y ¿democratización?»): del reformismo a la política social (1880-1924)» en Ángeles BArrio Alonso, Andrés Hoyo Aparicio, Manuel SuArez Cortina (eds.), Latidos de nación. Europa del Sur e Iberoamérica en perspectiva histórica, Zaragoza, PUZ (en prensa).

BERAMENDi GONZÁlez, Justo, «Republicanismo federal y nación española en el siglo XIX», en Fernando MARTínez LopeZ, María Isabel RUIZ García (eds.), El republicanismo de ayer a hoy, Madrid, Biblioteca Nueva, 2012, pp. 71-92. 
BERAMENDI, Justo, «Identidades/Culturas políticas de regionalismos y nacionalismos subestatales (1875-1936)», en Carlos ForCADELL, Manuel SuÁrez CoRTINA (eds), La Restauración y la República, 1874-1936, vol. III, Historia de las culturas políticas en España y América Latina, Madrid, Marcial Pons, Prensas Universitarias de Zaragoza, 2015, pp. 377-402.

BERNECKER, Walther, «Nación, nacionalismo y nacionalización en España: el debate continúa», en Iberoamericana, vol. 16, n.61 (2016), pp. 267-280.

BILlig, Michael. Banal Nationalism, London, Sage, 2004.

BoокCHIN, Murray, Anarquismo social, anarquismo personal, Madrid, Virus, 2012.

Carantoña Alvarez, Francisco, Balado Insunza, Francisco (eds.). Gumersindo de Azcárate. La conciencia democrática de una época. León, Diputación de León/Instituto Leonés de Cultura, 2019.

De la Calle Velasco, María Dolores, La Comisión de Reformas Sociales, 1883-1903: política social y conflicto de intereses en la Restauración. Madrid, Ministerio de Trabajo y Seguridad Social, 1989.

De la Calle Velasco, María Dolores, «La Comisión de Reformas Sociales: la primera consulta social al país», en Juan Ignacio PALACiO MoRENA (coord.), La reforma social en España. En el centenario del Instituto de Reformas Sociales. Madrid, C.E.S. 2004, pp. 39-69.

De RiQuer, Borja, «La débil nacionalización española del siglo XIX», Historia Social, 20 (1994), pp. 97-114.

DíEz, Xabier, L’Anarquisme, fet diferencial catalá, Influència i llegat de l'anarquisme en la historia i la societat catalana contemporània, Madrid, Virus, 2013.

DuARTE, Ángel, «Republicanismo unitario y republicanismo federal hasta 1873. Algunas consideraciones», en Javier MORENo LuZón (ed.), Izquierdas y nacionalismos en la España contemporánea, Madrid, Editorial Pablo Iglesias, 2011, pp. 41-65.

DuARTE, Ángel, «Cultura republicana», en Carlos ForCADELl, Manuel SuÁREZ CorTina (eds.), La Restauración y la República, 1874-1936, vol. III, Historia de las culturas políticas en España y América Latina, Madrid, Marcial Pons, Prensas Universitarias de Zaragoza, 2015, pp. 229-254.

FERnÁndez GómEZ, Francisco, «La Barcelona de los exiliados, antipatriotas, desertores, prófugos y solidarios. Internacionalismo y cosmopolitismo anarquista en el último tercio del siglo XIX», en Pere GABRIEL, Jordi POMÉs, Francisco FERnÁndez Gómez (eds.). España Res Pública. Nacionalización española e identidades en conflicto (siglos XIX y XX), Granada, Comares, 2013, pp. 271-283.

FORCADELL, Carlos, «Los socialistas y la nación», en Carlos ForCADELL, Ismael SAZ, Pilar Salomón (eds.), Discursos de España en el siglo XX, Valencia, PUV, 2009, pp. 15-34. 
Ángeles Barrio Alonso

GABRIEL, Pere, «Las bases políticas e ideológicas del catalanismo de izquierdas del siglo XX», Espacio, Tiempo y Forma., Serie V. Historia Contemporánea, 13 (2000), pp. 73-103.

GARCía BALAÑá, Albert, La fabricació de la fàbrica: treball i política a la Catalunya cotonera, 1784-1874, Barcelona, Publicacions de l'Abadia de Montserrat, 2004.

García BALAÑÁ, Albert, «"Ya no existe Partido Progresista en Barcelona”. Experiencia social y protesta obrera en la insurrección republicana de 1869», Hispania, vol. LXVIII, 230 (2008), pp. 735-759.

GARCÍA BALAÑÁ, Albert, «Clase, pueblo y patria en la España liberal. Comunidades polisémicas y experiencias plebeyas en la Cataluña urbana, 1840-1870», en Fernando Molina APARicio (ed.), Extranjeros en el pasado. Nuevos historiadores de la España Contemporánea, Vitoria, Universidad del País Vasco, 2009, pp. 97-128.

GARCIA CARRIÓN, Marta, «Cultura nacional y nacionalismo español», en Carlos ForCAdell, Manuel SuÁrez Cortina (eds.), La Restauración y la República, 1874-1936. vol. III, Historia de las culturas políticas en España y América Latina, Madrid, Marcial Pons, Prensas Universitarias de Zaragoza, 2015, pp. 169-198.

GARrido, Fernando, Historia de las clases trabajadoras, Algorta, Zero, 1970 (Vol. 1).

Giron SIERrA, Álvaro, «Darwinismo, darwinismo social e izquierda política (1859-1914): reflexiones de carácter general», en Marisa MiRANDA, Gustavo VAllejo (comps.), Darwinismo social y eugenesia en el mundo latino, Buenos Aires, Siglo XXI, 2005, pp. 23-59.

Goldman, Emma, «Patriotismo, una amenaza para la libertad», La palabra como arma, La Plata, Anarres, 2010.

Jover ZAMORA, José María, «Conciencia burguesa y conciencia obrera en la España contemporánea» en Política, diplomacia y humanismo popular. Estudios sobre la vida española del siglo XIX, Madrid, Turner, 1976, pp. 45-82.

LORENZO, Anselmo, El proletariado militante, Valencia, Sempere, s.f.

Lorenzo, Anselmo, Acracia o República, Refutación al discurso pronunciado por D. Luis Carreras el día 20 de febrero de 1886 en la fiesta del Círculo Democrático Federal Instructivo de Sabadell, Sabadell, Imprenta y Litografía de Juan Comas y Faura, 1886.

LoREnZO, Anselmo, El criterio libertario. Madrid, Dogal, 1977.

Lorenzo, Anselmo, El pueblo. Estudio libertario, Valencia, Sempere, s.f.

MELLA, Ricardo, «Evolución y revolución», conferencia pronunciada en el Círculo Federal de Vigo en 1891, recogida en Ricardo Mella, Forjando un mundo libre, Madrid, La Piqueta, 1977, pp. 65-75.

Mella, Ricardo, Ideario, Barcelona, Producciones Editoriales, 1978.

Moreno LuZón, Javier, NúÑEz SeIXAs, Xosé M. (eds.), Ser españoles. Imaginarios nacionalistas en el siglo XX, Barcelona, RBA, 2013. 
Palacio Morena, Juan Ignacio, La institucionalización de la reforma social en España. La Comisión y el Instituto de Reformas Sociales, Madrid, Ministerio de Trabajo y Seguridad Social, 1988.

PÉrez GARZón, Juan Sisinio, «Encrucijadas historiográficas de los nacionalismos en España», en José Luis De LA Granja. (coord.), La España del siglo XX a debate. Homenaje a Manuel Tuñón de Lara. Madrid, Tecnos, 2017, pp. 17-51.

PÉrez LedeSma, Manuel, Ismael SAZ (dirs.), Historia de las culturas políticas en España y América Latina, Madrid, Marcial Pons/Prensas de la Universidad de Zaragoza, 2013-2016.

Pérez Ledesma, Manuel, Sierra, María (eds.), Culturas políticas: teoría e historia. Zaragoza, Institución Fernando el Católico, 2011.

Pi y Margall, Francisco, Las Nacionalidades, Introducción y Notas: Antoni Jutglar, Madrid, Cuadernos para el diálogo, 1973.

RECLus, Elisée, Evolución, revolución y anarquismo, Buenos Aires, Proyección, 1969.

Romeo Mateo, María Cruz, «La construcción del Estado y el fomento de la identidad nacional española ¿una dinámica fracasada?», en Ángeles BARRIO Alonso, Aurora Garrido Martin (dirs.), Provincia, región y nación en la España Contemporánea, Santander, Parlamento de Cantabria/PUbliCan, 2011, pp. 41-61.

SALOMÓN CHÉLIZ, Pilar, «Republicanismo e identidad nacional española: la República como ideal integrador y salvífico de la nación» en Carlos ForCADELL, Ismael SAZ, Pilar SALOMÓn (eds.), Discursos de España en el siglo XX, Valencia, PUV, 2009, pp. 35-64.

SALOMÓN CHÉLIZ, Pilar, «Internacionalismo y nación en el anarquismo español anterior a 1914», en Ismael SAZ, Ferran ARCHILÉS (eds.), Estudios sobre nacionalismo y nación en la España contemporánea, Zaragoza, Prensas Universitarias de Zaragoza, 2011, pp. 137-168.

Serrano, Carlos, «Patriotisme, questions coloniales et mouvements ouvriers en Espagne à la fin du XIX siècle», Le Mouvement Social, 128 (1984), pp. 15-25.

SMiTH, Ángel, «Los anarquistas y anarcosindicalistas ante la cuestión nacional», en Javier MoReno (ed.), Izquierdas y nacionalismos en la España contemporánea, Madrid, Editorial Pablo Iglesias, 2011, pp. 141-156.

Suarez Cortina, Manuel, Ridolfi, Maurizio (eds.), «Estado y nación: unitarismo y federalismo en la Europa del Sur», en Manuel Suarez Cortina, Maurizio RIDOLFI (eds.), El Estado y la Nación. Cuestión nacional, centralismo y federalismo en la Europa del Sur, Santander, Ediciones Universidad de Cantabria, 2013, pp. 9-26.

VILAR, Pierre, «Mouvement ouvrier espagnol et questions nationales: quelques réflexions préliminaires», Le Mouvement Social, 128 (1984), pp. 7-14. 


\section{Financiación}

Este trabajo forma parte del proyecto PGC2018-099075-B-100 CONAIBER La construcción nacional en el mundo iberoamericano. 18001939.

\section{Datos de la autora}

Ángeles Barrio Alonso es catedrática de Historia Contemporánea en la Universidad de Cantabria, la mayor parte de su obra publicada trata de la historia del anarquismo, los movimientos sociales y las culturas políticas de la izquierda, las relaciones laborales y las políticas sociales, con particular dedicación en los últimos años al análisis de estos temas en al ámbito de la Europa del Sur y América Latina. 